\title{
The COVID 19 Pandemic and Colorectal Cancer: 5W1H - What Should We Do to Whom, When, Why, Where and How?
}

\author{
COVID-19 Pandemisi ve Kolorektal Kanser : 5N1K- Neyi, Neden, Nasıl, \\ Nerede, Ne Zaman ve Kime Yapalım?
}

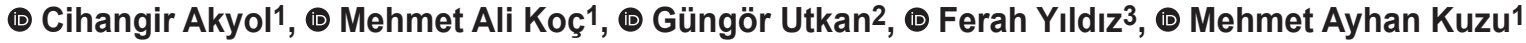 \\ ${ }^{1}$ Ankara University Faculty of Medicine, Department of General Surgery, Ankara, Turkey \\ ${ }^{2}$ Ankara University Faculty of Medicine, Department of Medical Oncology, Ankara, Turkey \\ ${ }^{3}$ Hacettepe University Faculty of Medicine, Department of Radiation Oncology, Ankara, Turkey
}

\section{IIIIIIII ABSTRACT}

The treatment of colorectal cancer, which is an important cause of cancer related death and is still an important public health problem, has become a matter of debate due to the COVID-19 pandemic that emerged in December 2019. This pandemic has forced us to rearrange our entire surgical practice. However, during these arrangements it should be ensured that patients are less affected by the pandemic, hospital resources should be used more efficiently and the risk of healthcare professionals should be minimized. This study discusses how to plan the multimodal treatment of colorectal cancer during the pandemic by using surgical, chemotherapeutic, and radiotherapeutic options while evaluating tailored treatments and the current international guidelines.

Keywords: Colorectal cancer, COVID-19, pandemic, SARS-CoV-2

\section{||||||||||| ÖZ}

Kansere bağlı ölümlerin önemli bir nedeni olan ve halen önemli bir toplum sağlığı sorunu olan kolorektal kanserin tedavisi, Aralık 2019'da ortaya çıkan COVID-19 pandemisi nedeniyle tartışma konusu halini almıştır. Yapılacak düzenlemeler hastaların pandemiden daha az etkilenmesini, hastane kaynaklarının pandemi için daha etkili kullanılmasını sağlamalı, sağlık çalışanlarını riske sokmadan planlanmalıdır. Ancak onkolojik ve cerrahi sonuçların bu yapılacak tedavi değişikliklerinden etkilenmemesi ana amaç olmalıdır. Bu çalışmada, kişiselleştirilmiş tedavi ile güncel uluslararasıı kılavuzlar da tartışılarak, pandemi döneminde kolorektal kanserin cerrahi, kemoterapi, radyoterapi seçenekleri kullanılarak multimodal tedavisinin nasıl planlanacă̆ı tartışılmıştır.

Anahtar Kelimeler: Kolorektal kanser, COVID-19, pandemi, SARS-CoV-2

\section{Introduction}

After the outbreak of the new coronavirus (Sars-CoV-2) in Wuhan-China in December 2019, the World Health Organization declared it as pandemic on March 11, 2020. After the diagnosis of the first case of Corona Virus Disease 2019 (COVID-19) in Turkey on March 11, 2020, the Ministry of Health of the Republic of Turkey recommended postponing all elective surgeries on March 17, 2020, to lower the workload in hospitals and to prevent the disruption of healthcare services that will be required in the future period. After these developments, the approach towards the surgical treatment of colorectal cancer patients has been the subject of debate among healthcare professionals. Is colorectal cancer surgery an emergency or elective procedure or one for which conditions necessitate emergency surgery? Should we continue the colorectal procedures as if nothing

Address for Correspondence/Yazışma Adresi: Mehmet Ayhan Kuzu MD, 
has happened, or should the operations be delayed? How long can colorectal operations be postponed without harming patients? Regarding these questions, the purpose of this review was to establish optimal colorectal cancer management during the COVID-19 pandemic.

\section{Colorectal Cancer Treatment During the COVID-19 Pandemic}

"Treat the patient, not the disease".

Tailored therapy is the most important step in the treatment of colorectal cancer. The evaluation of five different steps and management of colorectal cancer patients regarding tailored therapy has gained more importance these days.

\section{Factors to Consider in the Treatment Planning}

\section{Identifying Patients at Risk}

The patient's age and concomitant diseases need to be evaluated thoroughly. Most deaths during the COVID-19 outbreak are in the group of over 60 years of age, and particularly in those with comorbid diseases. Unfortunately, colorectal cancer is frequently seen in this age group. Furthermore, the review of the risk factors of patients who have died during the COVID-19 outbreak has shown that the infection had an unfavourable course in patients with coronary heart disease, chronic pulmonary disease, diabetes, hypertension, immunosuppressive diseases (cancer, postorgan transplantation, steroid use and chronic kidney failure), autoimmune diseases, severe obesity and in those who are smokers. Moreover, male sex mortality rates are higher in the COVID-19 pandemic. ${ }^{1,2}$

Other conditions that should not be overlooked are the evaluation of the patient's performance (Karnofsky or WHO score) and the nutritional condition. During the treatment of colorectal cancer, these characteristics of the patient should also be evaluated.

\section{Clinical Presentation}

In our country, approximately $20 \%-25 \%$ of patients with colorectal cancer initially present to the emergency departments. Therefore, patients with tumour obstruction, perforation or blood loss need to be evaluated separately. The fact that some patients do not present to the emergency department despite having abdominal and defecation complaints that impair their quality of life should be considered. However, if the outbreak is prolonged, we will encounter cases in advanced stages since elective colonoscopy would be performed more rarely.

\section{Tumour Characteristics}

In every patient diagnosed with colorectal cancer, clinical staging and radiological evaluation of the lung and the entire abdomen are necessary. Based on the clinical staging, the disease should be classified as early, local, regional (presence of lymph node metastasis) or systemic. However, overcrowding in radiology clinics could limit the staging. In addition, patients without clinical findings, but with radiological subileus or closed perforation, should also be considered as an emergency.

\section{Surgical Risk Factors}

The treatment plan should be made after clinical staging considering the morbidity, length of surgical procedure, the estimated length of hospital stays, the need for intensive care unit (ICU) and the need for blood/blood products. Scoring systems for morbidity risk estimations can be used for this purpose (https://riskcalculator.facs.org/RiskCalculator/). ${ }^{3}$ Furthermore, the preoperative risk assessment of the patients by the American Society of Anesthesiologists Classification is also critical in the decision-making process (For example, long and complicated surgeries, such as cytoreductive surgery and hyperthermic perfusion or pelvic exenteration, would not be appropriate during this period).

In emergency or elective surgeries that cannot be deferred, it will be appropriate to prefer procedures, such as stoma only or resection and stoma, to reduce risks.

\section{The Condition of the Healthcare System}

The COVID-19 pandemic is progressing day by daily, affecting the healthcare system in different ways. Therefore, the conditions of healthcare workers, the availability of a separate operating room and separate ICU for surgical patients in hospitals should also be evaluated.

\section{What Should be the Best Treatment Option for Colorectal Cancer?}

Based on the experience gained from colorectal cancer patients in China and Italy, several associations have published guidelines and/or recommendations to protect both patients and healthcare professionals and to provide uninterrupted services to patients when necessary. ${ }^{4,5,6,7}$

The general trend in these publications is to postpone elective surgery as much as possible but to perform emergency surgery provided that general measures are taken. The situation regarding colorectal cancer surgery appears to be more complicated. While there is no debate about performing surgery for emergency conditions such as obstruction or perforation, other conditions associated with colorectal cancer require further consideration of the status of the patient, the stage of the tumour, the risk of the surgical procedure and the condition of the respective hospital.

\section{The Guidelines and Recommendations of International Associations}

The "COVID-19 Guidelines for Triage of Colorectal Cancer Patients" of the American College of Surgeons, recommend 
approaching each case individually based on three different scenarios for colorectal cancer surgery. ${ }^{5}$

I- In the first scenario, if the number of COVID-19 patients in the hospital is limited and the hospital has sufficient capacity, surgery is recommended as soon as possible in nearly obstructing colorectal cancers, tumours requiring frequent blood transfusions, rectal cancers nonresponsive to neoadjuvant therapy. These early-stage cancers that do not require neoadjuvant-adjuvant therapy and in tumour with suspected local perforation or sepsis.

Prophylactic surgeries required for Hereditary syndromes, small colon or rectal carcinoids, large polyps and even malignant polyps can be deferred for three months.

II- In the second scenario where the number of COVID-19 patients is increasing and the ICU and ventilator capacity is limited, emergency surgery is recommended in cases with nearly obstructing colon cancer where stenting is not an option, in nearly obstructing rectal cancer, in patients requiring high blood transfusions (inpatient) and in cases with pending evidence of local perforation or sepsis.

III- In the third scenario where ICU is at full capacity and the need for ventilators cannot be met due to patient overcrowding in hospitals due to progression of the pandemic, surgery is recommended only for colorectal cancer patients with perforating, obstructing, actively bleeding tumours (inpatient transfusion-dependent) or septic patients. ${ }^{5}$

Similarly, the guidelines published by the Society of American Gastrointestinal and Endoscopic Surgeons (SAGES) only recommend surgical intervention in cancer patients who are likely to progress or who require emergency intervention. ${ }^{\top}$

The Association of Coloproctology of Great Britain and Ireland has a much more conservative approach and recommends alternative strategies such as colonic stenting for patients with obstruction, and even percutaneous drainage for cases with perforation if the patient is suitable and the resources of the hospital are sufficient. ${ }^{4}$ If despite all, surgical treatment is required, it is recommended to perform a preoperative risk assessment by consulting anaesthesiologists and intensive care specialists as well and make decisions based on hospital resources. The rationale for this conservative approach is to avoid the growth of overall mortality because of the high environmental risk posed by COVID-19 and the efforts for the careful use of hospital resources. Therefore, it is recommended to determine the urgency or emergency of the clinical condition by considering the presenting condition, symptoms and the disease severity at admission. Also, it is recommended that either planned or unplanned need for ICU should be estimated, optional strategies to reduce this need should be mediated and potential capacity of ICU should be considered. ${ }^{4}$
During the COVID-19 pandemic, one of the points to be considered when deciding on surgery in colorectal cancer patients is the current condition of the hospital. It is necessary to ask the questions of how long we can keep colorectal cancer patients waiting due to the insufficient hospital capacity and the sharp increase in the numbers of COVID-19 cases.

Several studies report different results regarding the length of time for the deferral of colorectal cancer surgery. A large-scale population-based study analysed 39,000 newly diagnosed colorectal cancer patients. The study compared the survival by the time elapsing from diagnosis to treatment separately for each disease. It was observed that the survival rates were significantly different across patient groups treated within 30 days, in the 31-150 days and $>151$ days of diagnosis. ${ }^{8}$ In a retrospective study comparing the time between the moment of diagnosis and treatment (surgical or neoadjuvant treatment) in the colon and rectal cancer, separate analyses were performed both for 35 days and 49 days. No difference was identified between the patients in whom treatment had commenced within 35 days and patients whose treatment began after 35 days concerning survival. Similar results were also obtained when the same data were examined for day 49. ${ }^{9}$ In another study, Wanis et al. ${ }^{10}$ compared 908 stage I-III colon cancer patients concerning disease-free survival and overall survival according to the time from diagnosis to surgery. The comparison of those who had surgery earlier or later than 30 days revealed that there was no difference in overall survival or disease-free survival. Furthermore, there was no difference even when the threshold was taken as 60 and 90 days. Flemming et al. ${ }^{11}$ also compared 4326 stage I-IV colon cancer patients concerning overall survival and cancer-specific survival according to the time to surgery. In patients with the time to surgery $>42$ days, no difference was identified in overall survival and cancer-specific survival. In a larger-scale retrospective cohort study conducted by Kucejko et al. ${ }^{12}$, it was identified that the best survival values were in those operated between 3-6 weeks. The reason for this is thought to be the need to take enough time during the first weeks after the diagnosis to perform proper staging, and also that the patients can be made more suitable for the surgery particularly concerning their cardiac, pulmonary and nutritional conditions. Considering all these studies, it may be thought that elective colon cancer surgery can be deferred for approximately six weeks.

In rectal surgery, it has been shown that when the time between the first symptoms and treatment is longer than 60 days, the rate of survival is lower. ${ }^{13}$ In their large cohort study, Yun et al. ${ }^{14}$ determined that the deferral of surgery for longer than 30 days was associated with poor survival in rectal cancer. In other words, it appears possible to wait 
30 days without affecting survival in rectal cancer as well. It takes 2-3 weeks from the time of diagnosis to surgery or neoadjuvant treatment in many specialised centres on colorectal surgery. Advanced imaging and/or preoperative preparations are performed during this period. However, even a 6-week deferral for rectal cancer surgery similar to the optimum deferral period for colon cancer may not be sufficient to avoid the exhaustion of hospital resources in a potential crisis like the one experienced in Italy. ${ }^{15}$

Today, another approach in rectal cancer is the total neoadjuvant therapy (TNT) approach. ${ }^{16}$ The Society of Surgical Oncology states that if feasible, the TNT option should also be considered in rectal cancer cases. ${ }^{17}$ It should also be remembered that patients receiving long-term neoadjuvant therapy or TNT will need to visit hospital facilities regularly, resulting in an increased risk of COVID-19 transmission and a higher demand for the use of hospital resources. Therefore, the balance between relatively higher hospital admissions of a patient managed with TNT and the risk of colorectal surgery should be well characterised during the era of the COVID-19 pandemic. ACPGBI recommends short-term radiotherapy for rectal cancers to rule out this possibility. ${ }^{6}$ Phase III studies comparing short-term radiotherapy and long-term chemoradiotherapy have failed to show a difference in local control, disease-free and general survival between these two approaches. ${ }^{18,19}$ Although longterm chemoradiotherapy is preferred in distal rectal cancers that have invaded the sphincters, the nearby organs or have a positive lateral lymph node, it should not be overlooked that these patients will be spending a long time in the hospital during the pandemic. It is for this reason that even without the COVID-19 pandemic, short-term radiotherapy is being used more frequently today. Short-term radiotherapy will reduce the use of hospital resources and, more importantly, the risk of patient and healthcare workers being infected.

Moreover, it should be considered an option that even patients who can be referred directly to surgery can receive shortterm radiotherapy by expanding the indication if needed ${ }^{6}$ In rectal cancer, surgery after neoadjuvant radiotherapy can be planned in eight or even 12 weeks at the latest. ${ }^{5,6}$ Moreover, if there is a good response after neoadjuvant therapy, and it is feasible to deliver additional chemotherapy, surgery could be deferred even further. ${ }^{5}$ In patients with a complete response after neoadjuvant therapy, the "wait and see approach" could also be suggested by closely monitoring the patient and discussing the situation with the patient. ${ }^{6}$ In locally advanced and recurrent rectal cancers and metastatic colorectal cancers, chemotherapy can be considered as an option to defer surgery. ${ }^{5}$ It is recommended to make all these decisions in the multidisciplinary tumour (MDT) board and to inform the patient in detail. ${ }^{6,7}$
During the COVID-19 pandemic, the principles of radiation oncologists are grouped in three for the treatment of rectal cancer, similar to the treatment of all other tumours: postponing treatment if the patient's survival and/or local control is not being put at risk if treatment cannot be deferred to complete treatment in the shortest time feasible using hypofractionated plans and to ensure the safety of the patient and the treatment team. The Turkish Radiation Oncology Association has provided all the necessary information to all its members. It has notified them of all the precautions necessary in items by considering the recommendations of the hospital infection committees and, in particular, the publications from Wuhan and Italy.

Another important issue for patients is the quality of life in the deferral period with cancer besides the impact of the COVID-19 pandemic. Studies have shown that the quality of life is also unfavourably affected in those patients. ${ }^{20}$

Before deciding to treat colorectal cancer cases immediately or later, it would be beneficial to remember one more subject. Although the adenoma-carcinoma sequence takes about 7-10 years for colorectal cancer to develop, this process may decrease to 2-3 years in familial and hereditary colorectal cancers. In other words, the progression of the disease occurs in a shorter time in familial and hereditary colorectal cancers. This condition should also be considered when deciding whether to defer treatment. Another issue to consider within this context is that patients younger than 50 years old present at advanced stages and with an unfavourable prognosis. This explains why colorectal cancer is the first among cancer--related deaths under the age of $50 .{ }^{21}$

Another point that should be known when the treatment plan is being made is that the pandemic is also expected to last 3-4 months in our country, as in China and Italy.

\section{Surgical Timing Decisions for Colorectal Cancer Patients During the Pandemic}

Based on the assessment of all these data, it would be appropriate to classify colorectal cancer patients in four stages according to the treatment priority. However, all the factors discussed above should be involved in the treatment decision, including patient-related factors, mode of presentation, the characteristics of the tumour, the morbidity of the surgical procedure and the infrastructure of the hospital (Table).

\section{1- Emergency Patients}

Patients with radiologically confirmed or clinically diagnosed obstruction, perforation and massive bleeding should be operated immediately. 


\section{2- Asymptomatic Patients}

In general, during the outbreak in our country, it will be appropriate to defer elective colorectal cancer surgery for 30 days and decide again at the end of this period. However, some patients are seriously concerned that the pandemic may become prolonged, and this will increase the waiting time and lead to progression. In addition, during this waiting period, psychological disorders, such as severe anxiety and depression, may also develop. These patients can be operated in hospitals not providing healthcare services for patients affected by the pandemic or in hospitals, maintaining the appropriate standards after informing patients about the risk of COVID-19 infection and obtaining their informed consent.

When deciding to defer, the opinion of infectious diseases specialists and epidemiologists becomes important. Opinions should be sought before postponing for 1 to 1.5 months. If the pandemic is anticipated to progress during this period, the patient and the physician may need to evaluate the medical decision within the current circumstances. It is important that this decision should also be included in the patient's file in written form with its reasons.

\section{i. Surgical Timing in Colon Cancer}

Patients diagnosed as a result of screening tests are generally asymptomatic and stage I-II patients. It is known that the oncological outcomes of stage I-II colon cancer found in radiological staging will not be affected unfavourably by the deferral of the treatment for 30 days. If patients need to wait for more than 30 days, the risks of COVID-19 should be explained thoroughly, consent should be obtained and a joint decision should be made. At the end of the 30day deferral, the patient can be interviewed online, and the treatment can be deferred further for an extra month depending on the current situation of the healthcare facility and the patient's symptoms. However, a need for a further deferral at the end of the 60-day-period warrants radiological staging for decision making in those patients. Furthermore, in asymptomatic but stage III colon cancer patients, it is known that the first 30-day deferral period would not affect the oncological outcomes. However, if deferral will be longer than 30 days, discussing a plan of neoadjuvant chemotherapy (oral regimens if possible) in an online MDT board will be appropriate. In asymptomatic stage IV colon cancer patients, it is possible to identify the chemotherapy

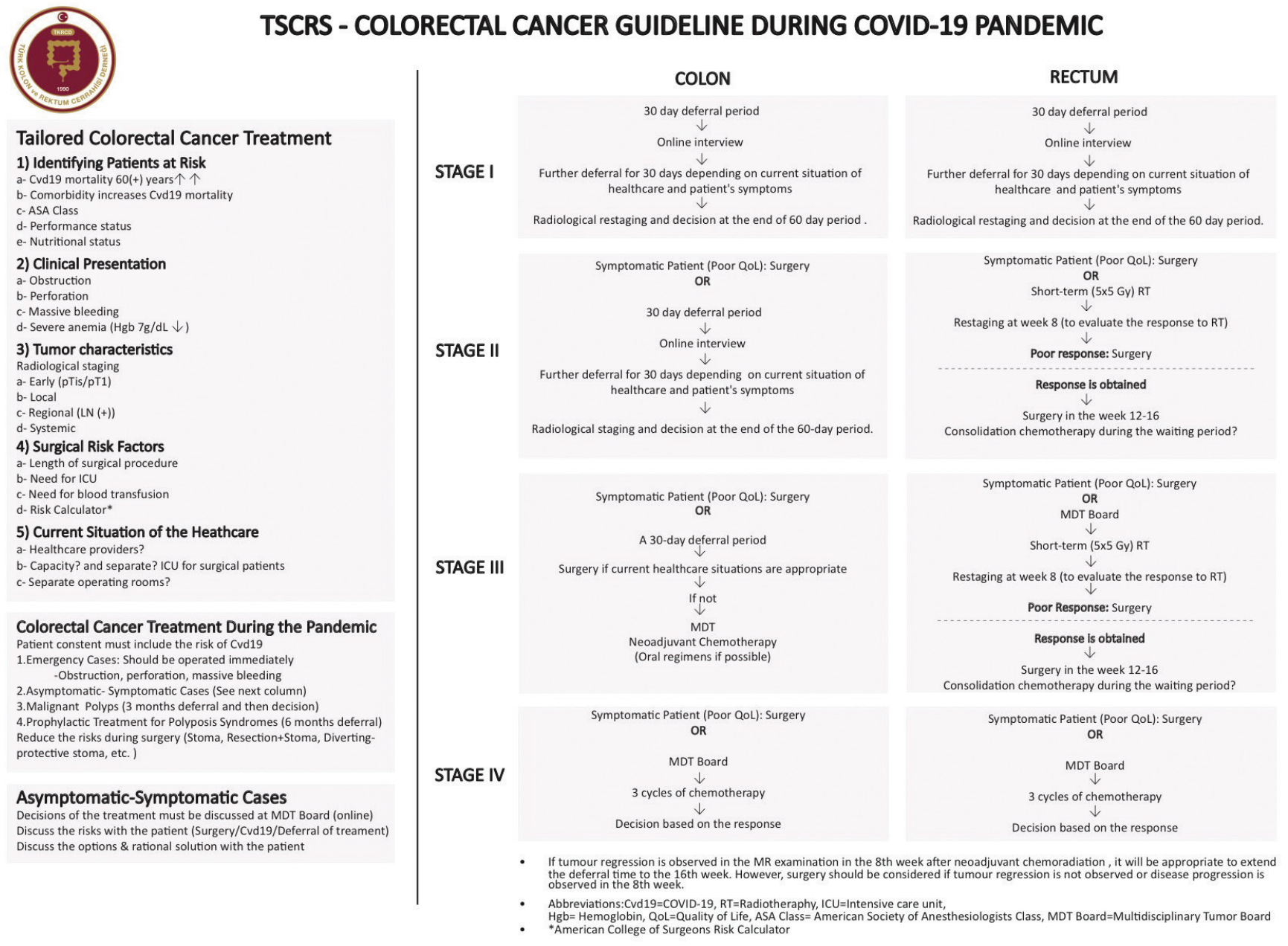


protocols in the MDT board based on the status of systemic diseases and to continue chemotherapy or to plan surgery depending on the radiological response after three courses of chemotherapy (Table).

\section{ii- Surgical Timing in Rectal Cancer}

Similarly, cases detected as a result of screening are generally asymptomatic. It is known that for 30-day deferral in stage I rectal cancer cases would not affect the oncological outcomes. If patients need to wait for more than 30 days, the risks of COVID-19 should be explained thoroughly, consent should be obtained, and a joint decision should be made. At the end of the 30-day delay, the patient should be contacted online and depending on our country's condition and the patient's symptoms, treatment can be deferred for another month. However, if it is required to defer once again at the end of the 60 days, in such cases, radiological staging is necessary to make a new decision. Even though radiotherapy is not indicated for all patients with stage II rectal cancer, a short-term ( $5 x 5 G y$ ) radiotherapy could be administered to gain time during the pandemic. Then, the radiotherapy response should be evaluated in the eighth week after radiotherapy. If there is a regression with radiotherapy, it will be feasible to prolong the waiting period up to 12 or even 16 weeks. In stage III rectal cancer cases, although radiotherapy is not indicated for all patients, during the pandemic, it is recommended to deliver short-term (5x5Gy) radiotherapy and to assess the response to radiotherapy in the eighth week after radiotherapy. If there is a regression with radiotherapy, it would be feasible to prolong the waiting period up to 12 or even 16 weeks. In stage II and III cases, during the waiting period, the consolidation chemotherapy protocol should also be discussed in the MDT board. In stage II and III patients, if there is no regression in the eighth week with radiotherapy, the decision for surgery can be made depending on the infrastructure of the hospital. The long-term radiotherapy protocol will not be appropriate during the pandemic period, as it increases the length of stay in the hospital, resulting in raising the risk of transmission. It is necessary to choose protocols that will minimise the patient's hospitalisation for both radiotherapy and chemotherapy procedures.

In addition, in rectal cancer patients who have received neoadjuvant chemoradiotherapy (long-term) before the pandemic, the response should be assessed in week 8 and if there is a good response, the delay should be completed to 16 weeks. If the patient is not a good responder surgery should be planned.

\section{3- Symptomatic Patients}

In these patients, the decision for surgery can be made without a delay, depending on the severity of symptoms and findings, and their effect on the quality of life. The presence of symptoms and findings that impair the general condition of the patient are important for the decision of surgery (blood transfusion need, persistent abdominal pain, tenesmus, severe diarrhoea, severe weight loss, other symptoms). Symptomatic patients are generally those between stages II-IV. It is necessary to plan treatment after identifying the clinical-stage by good radiological staging. For patients who are symptomatic but can wait, deferral of the surgery during the pandemic should be preferred. The treatment according to the stages is as described for asymptomatic stage I, II and III.

Another issue that should not be forgotten is to select the protocols that will minimise the patient's hospitalisation for both radiotherapy and chemotherapy procedures. Therefore, TNT approaches may not be feasible in stage III rectal cancer.

\section{4- Malignant Polyp - Patients Scheduled for Prophylactic Surgery}

It will be appropriate to postpone prophylactic surgeries in patients who have undergone polypectomy and have been diagnosed with malignant polyps, and in inherited polyposis syndromes.

\section{What to Do in Patients Who Have a Surgical Decision?}

When deciding on surgery, the resources of the hospital should be evaluated first. If the resources are not sufficient, the patient should be referred to a COVID-free hospital in your region. These patients in the risk group should be informed not only about the surgery they will undergo but about the risk of COVID-19 infection as well. ${ }^{7}$ The risk of infection with SARS-CoV-2 must also be added to the consent that will be obtained. Patients should be questioned very carefully regarding the history of COVID-19 during the preoperative period. In patients who are scheduled for elective surgery, the PCR test must be performed 14 days before the operation date, and patients with a negative test should be asked to come to the hospital after absolute isolation at home. To the patients that come to the hospital, a repeat PCR test and computed thorax tomography should be performed 24 hours before the surgery. In cases in which the patient's evaluation results are suitable, elective surgery can be performed. Otherwise, they should receive COVID-19 therapy. Patients who require emergency surgery should be regarded as cases of suspected COVID-19, and a computed tomography of the abdomen and thorax must be obtained. ${ }^{4}$ It is essential that all staff should be careful and follow the protocols during the preoperative and postoperative period to prevent infection for all patients hospitalised for surgery. In the operating room, the staff and the doctors are required to operate using personal protective equipment., ${ }^{4,22}$ 


\section{Does Minimally Invasive Surgery (MIS) Increase the Risk of Transmission?}

It is known that the SARS-CoV-2 virus is an enveloped virus that is transmitted by droplets. ${ }^{23,24}$ Furthermore, reverse transcription polymerase chain reaction tests demonstrate that the virus tested positive in the stool of approximately $30 \%$ of patients. ${ }^{25}$ It is not known whether there is a risk for infection in MIC/laparoscopic or open abdominal surgery. Nevertheless, because viruses such as Corynebacterium, papillomavirus and HIV can be present in surgical smoke, SARs-CoV-2 may also be present in the smoke caused by energy devices and the cautery or the pneumoperitoneum created by $\mathrm{CO}_{2}$ during laparoscopy. ${ }^{26,27,28}$ Since the aerosol risk is much higher in laparoscopic surgery than open surgery, laparoscopic surgery is not recommended. ${ }^{4,6,29}$ Colleagues in China prefer open surgery. However, SAGES argue that the advantages of laparoscopic surgery, such as fewer complications and shorter hospital stays, should particularly be taken into consideration. ${ }^{7}$ They have stated that contrary to open surgery, nearly all the particles formed during dissection in laparoscopy can be cleared away using closed ultrafiltration systems.

Minimally invasive surgery (MIS) should not be preferred in patients who are known to be infected or suspected from their history and evaluations performed. However, in patients with negative test results and no signs of COVID-19 pneumonia on thorax computed tomography, MIC can be performed under strict precautions.

It is thought that very efficient filtering can be achieved when the smoke aspiration systems produced to provide a better view in laparoscopic surgery are used with an ultralow particulate air filter capable of filtering 0.05 microns. ${ }^{30}$ If the surgery is to be performed laparoscopically, to reduce the release of aerosols, it is recommended to cut port entrances small enough to avoid gas leaks, to use cautery and energy devices as minimally as possible, if possible only to use monopolar cautery with an aspirator, to maintain intraabdominal pressure at a minimum level, and to finalise the pneumoperitoneum using filtered smoke release systems before extracting the specimen, converting to open surgery for any reason and closing the port incisions. ${ }^{7,30}$

\section{Does Enhanced Recovery After Surgery (ERAS) Have a Role?}

The concept called enhanced recovery after surgery (ERAS) or the perioperative multimodal approach aims to discharge early from the hospital, return quickly to daily life, use various perioperative strategies to improve the recovery conditions, reduce the postoperative stress and integrate evidence-based medicine into patient management. It has been shown that ERAS protocols decrease the length of hospitalisation without affecting the risk of complications or re-hospitalisation.
Although individual components vary, most ERAS programmes include avoiding prolonged hunger, optimisation of comorbidities in the preoperative period, preoperative carbohydrate loading, targeted hemodynamic therapy, multimodal analgesia by avoiding opiates, avoidance or early removal of tubes (nasogastric tube, foley catheter and drains) and support of gastrointestinal functions. Early recovery is targeted as a result of these measures.

During the pandemic period, ERAS will not only ensure that the patient is discharged from the hospital earlier but will also prevent the contact of patient secretions and fluids with the surrounding environment by avoiding nasogastric catheter, drains and bladder catheter applications.

The development and widespread use of ERAS in combination with MIS represents a paradigm shift in perioperative care. Although ERAS protocols are mostly associated with laparoscopic surgery, and there will be an expected decline in performing MIS during this period, most ERAS protocols can also be implemented in open surgery. If the condition of the patient, the surgeon and the healthcare centre fulfil the requirements, the application of ERAS protocols will be beneficial for patients, surgeons and public health.

\section{How Will We Make the Final Decision in the Treatment of Colorectal Cancer Patients During the COVID-19 Pandemic?}

The risks that colorectal cancer disease and the COVID-19 pandemic impose on the healthcare system should be evaluated by momentary comparisons. The principle of 'treating the patient but not the disease' should be considered after reviewing the five factors in the treatment planning that were described above and have been assessed separately. The morbidity-mortality created by the operation (https:// riskcalculator.facs.org/RiskCalculator/) and COVID-19 should be assessed, and the final decision must be made accordingly.

\section{Conclusion}

According to the GLOBO CAN 2018 data, colorectal cancer continues to be a serious public health problem, ranking third among cancer-related deaths and fourth among the most common cancer types. ${ }^{31}$ During the COVID-19 pandemic, the surgical management of colorectal cancer should be planned to ensure that patients are less affected by the pandemic and hospital resources are used more effectively without putting healthcare workers at risk. However, the main purpose should be that the oncological and surgical results would not be affected by these treatment changes.

There is no need to change the surgical timing of conditions regarded as emergencies. However, in emergency surgeries, the use of MIS should be avoided, or appropriate technical equipment and protective equipment should be used. 
In cases where we consider it elective, postponing the surgical treatment of colorectal cancer for stage I and II patients for 4-8 weeks may be brought to the agenda. The MDT board must be held to discuss stage III patients and neoadjuvant treatment options should be evaluated for both the colon and the rectum. Short-term treatments and a longterm waiting period should be preferred in patients who are scheduled for radiotherapy.

MIS should not be used in cases known to be suspected or infected and should be used after all necessary precautions have been taken in non-infected patients.

ERAS applications should be placed on the agenda to benefit from the advantages of early discharge and to prevent the contact of the patient's body fluids with the external environment.

As a result, considering the point Turkey has reached during the pandemic, it appears highly likely that hospital resources will be mobilised for COVID-19 patients in the days ahead. Undoubtedly, emergency surgery should be performed. However, in such a case, the surgery of patients with colorectal cancer who are in the risk group should be deferred as much as possible after taking treatment precautions that will not affect patient survival, will not risk the patient's health, will not put healthcare professionals at any unnecessary risk, and will ensure the more appropriate use of hospital resources.

Peer-review: Internally peer reviewed.

\section{Authorship Contributions}

Concept: C.A., M.A.K., M.A.K., Design: C.A., M.A.K., M.A.K., Data Collection or Processing: C.A., M.A.K., G.U., F.Y., M.A.K., Analysis or Interpretation: C.A., M.A.K., G.U., F.Y., M.A.K., Literature Search: C.A., M.A.K., M.A.K., Writing: C.A., M.A.K., M.A.K.

Conflict of Interest: No conflict of interest was declared by the authors.

Financial Disclosure: The authors declared that this study received no financial support.

\section{References}

1. Siegel RL, Miller KD, Jemal A. Cancer statistics, 2018. CA Cancer J Clin 2018;68:7-30.

2. Brenner H, Bouvier AM, Foschi R, Hackl M, Larsen IK, Lemmens V, et al. Progress in colorectal cancer survival in Europe from the late 1980s to the early 21st century: The EUROCARE study. Int J Cancer 2012;131:16491658.

3. ACS. ACS Risk Calculator - Home Page [Internet]. 2019 [cited 2020 Apr 6]. Available from: https://riskcalculator.facs.org/RiskCalculator/

4. Urgent Intercollegiate General Surgery Guidance on COVID-19 | ACPGBI [Internet]. [cited 2020 Mar 29]. Available from: https://www.acpgbi.org. uk/news/urgent-intercollegiate-general-surgery-guidance-on-covid-19/
5. COVID-19 Guidelines for Triage of Colorectal Cancer Patients. [cited 2020 Mar 29]; Available from: https://www.facs.org/covid-19/clinical-guidance/ elective-case/colorectal-cancer

6. Considerations for Multidisciplinary Management of Patients with Colorectal Cancer during the COVID- 19 Pandemic. [cited 2020 Mar 29];(5962281):1-10. Available from: https://www.acpgbi.org.uk/news/ considerations-for-multidisciplinary-management-of-patients-withcolorectal-cancer-during-the-covid-19-pandemic/acpgbi-statement-oncrc-treatment-during-covid-19-final/

7. SAGES and EAES Recommendations Regarding Surgical Response to COVID-19 Crisis - SAGES [Internet]. [cited 2020 Mar 30]. Available from: https://www.sages.org/recommendations-surgical-response-covid-19/

8. Lee YH, Kung PT, Wang YH, Kuo WY, Kao SL, Tsai WC. Effect of length of time from diagnosis to treatment on colorectal cancer survival: A population-based study. PLoS One 2019;14:e0210465.

9. Strous MTA, Janssen-Heijnen MLG, Vogelaar FJ. Impact of therapeutic delay in colorectal cancer on overall survival and cancer recurrence - is there a safe timeframe for prehabilitation? Eur J Surg Oncol 2019;45:22952301.

10. Wanis KN, Patel SVB, Brackstone M. Do moderate surgical treatment delays influence survival in colon cancer? Dis Colon Rectum 2017;60:1241-1249.

11. Flemming JA, Nanji S, Wei X, Webber C, Groome P, Booth CM. Association between the time to surgery and survival among patients with colon cancer: A population-based study. Eur J Surg Oncol 2017;43:1447-1455.

12. Kucejko RJ, Holleran TJ, Stein DE, Poggio JL. How Soon Should Patients With Colon Cancer Undergo Definitive Resection? Dis Colon Rectum 2020;63:172-182.

13. Iversen LH, Antonsen S, Laurberg S, Lautrup MD. Therapeutic delay reduces survival of rectal cancer but not of colonic cancer. Br J Surg 2009;96:10-10.

14. Yun YH, Kim YA, Min YH, Park S, Won YJ, Kim DY, et al. The influence of hospital volume and surgical treatment delay on long-term survival after cancer surgery. Ann Oncol 2012;23:2731-2737.

15. Pellino G, Spinelli A. How COVID-19 Outbreak Is Impacting Colorectal Cancer Patients in Italy: A Long Shadow Beyond Infection. Dis Colon Rectum 2020;Available from: http://www.ncbi.nlm.nih.gov/pubmed/32205796

16. Fernández-Martos C, Garcia-Albeniz X, Pericay C, Maurel J, Aparicio J, Montagut $\mathrm{C}$, et al. Chemoradiation, surgery and adjuvant chemotherapy versus induction chemotherapy followed by chemoradiation and surgery: Long-term results of the Spanish GCR-3 phase II randomized trial. Ann Oncol 2015;26:1722-8.

17. Resource for Management Options of Colorectal Cancer During COVID-19 [Internet]. [cited 2020 Mar 30]. Available from: https://www. surgonc.org/wp-content/uploads/2020/03/Colorectal-Resource-duringCOVID-19-3.23.20.pdf

18. Bujko K, Nowacki MP, Nasierowska-Guttmejer A, Michalski W, Bebenek M, Kryj M. Long-term results of a randomized trial comparing preoperative short-course radiotherapy with preoperative conventionally fractionated chemoradiation for rectal cancer. Br J Surg 2006;93:1215-1223.

19. Ngan SY, Burmeister B, Fisher RJ, Solomon M, Goldstein D, Joseph D, et al. Randomized trial of short-course radiotherapy versus long-course chemoradiation comparing rates of local recurrence in patients with T3 rectal cancer: Trans-Tasman Radiation Oncology Group Trial 01.04. J Clin Oncol 2012;30:3827-3833.

20. Visser MR, van Lanschot JJ, van der Velden J, Kloek JJ, Gouma DJ SM. Quality of Life in Newly Diagnosed Cancer Patients Waiting for Surgery is Seriously Impaired. J Surg Oncol 2006;93:571-577.

21. Bhandari A, Woodhouse M, Gupta S. Colorectal cancer is a leading cause of cancer incidence and mortality among adults younger than 50 years in 
the USA: A SEER-based analysis with comparison to other young-onset cancers. J Investig Med 2017;65:311-315.

22. Kamer E, Çolak T. What to Do When A Patient Infected With COVID-19 Needs An Operation: A Pre-surgery, Peri-surgery and Post-surgery Guide. Turk J Color Dis 2020;30:1-8.

23. Lu R, Zhao X, Li J, Niu P, Yang B, Wu H, et al. Genomic characterisation and epidemiology of 2019 novel coronavirus: implications for virus origins and receptor binding. Lancet 2020;395:565-574.

24. Guan W, Ni Z, Hu Y, Liang W, Ou C, He J, et al. Clinical Characteristics of Coronavirus Disease 2019 in China. N Engl J Med 2020 ; [cited 2020 Mar 29];NEJMoa2002032. Available from: http://www.nejm.org/doi/10.1056/ NEJMoa2002032

25. Wang W, Xu Y, Gao R, Lu R, Han K, Wu G, et al. Detection of SARSCoV-2 in Different Types of Clinical Specimens. Jama 2020;doi: 10.1001/ jama.2020.3786. [Epub ahead of print].

26. Capizzi PJ, Clay RP, Battey MJ. Microbiologic activity in laser resurfacing plume and debris. Lasers Surg Med 1998;23:172-174.
27. Hensman C, Baty D, Willis RG, Cuschieri A. Chemical composition of smoke produced by high frequency electrosurgery in a closed gaseous environment: An in vitro study. Surg Endosc 1998;12:1017-1019.

28. Johnson GK, Robinson WS. Human immunodeficiency virus-1 (HIV-1) in the vapors of surgical power instruments. J Med Virol 1991;33:47-50.

29. Zheng MH, Boni L, Facs MD, Fingerhut A. Minimally invasive surgery and the novel coronavirus outbreak: lessons learned in China and Italy. Ann Surg 2020 Mar 26. doi: 10.1097/SLA.0000000000003924. [Epub ahead of print].

30. Resources for Smoke \& Gas Evacuation During Open, Laparoscopic, and Endoscopic Procedures - SAGES [Internet]. [cited 2020 Mar 30]. Available from: https://www.sages.org/resources-smoke-gas-evacuation-duringopen-laparoscopic-endoscopic-procedures/

31. Bray F, Ferlay J, Soerjomataram I, Siegel RL, Torre LA, Jemal A. Global cancer statistics 2018: GLOBOCAN estimates of incidence and mortality worldwide for 36 cancers in 185 countries. CA Cancer J Clin 2018;68:394424. 